\title{
Effect of bitumen emulsion on setting, strength, soundness and moisture resistance of oxychloride cement
}

\author{
M P S CHANDRAWAT ${ }^{\dagger}$, T N OJHA and R N YADAV* \\ Department of Chemistry, R N Ruia Government College, Ramgarh-Shekhawati (Sikar) 331 024, India \\ "Department of Chemistry, R R Government College, Alwar 301 001, India
}

MS received 8 November 2000; revised 2 April 2001

\begin{abstract}
Addition of bitumen emulsion to the matrix has been found to improve strength and soundness of the product while decreasing the initial setting periods. Thus, bitumen emulsion as an admixture in magnesia cement is a moisture proofing and strengthening material.
\end{abstract}

Keywords. Bitumen; emulsion; soundness; moisture proofing; oxychloride cement.

\section{Introduction}

Sorel's cement (oxychloride cement) discovered in 1867 has many properties superior to those of portland cement as observed by several researchers (Sorel 1867; Beaudin and Ramachandra 1975; Ved et al 1976; Beaudin et al 1977; Matkovic et al 1977; Mathur 1986; Chandrawat and Yadav 2000). The bitumen emulsion is an emulsified asphalt (a tarry black petroleum product) in aqueous medium. It has been reported to be a moisture proofing composition. Bituminous materials are often used for surface treatment, specially for roads. Such a treatment, without heavy foundation, suffices for pleasure vehicles and a medium amount of truck traffic. With a heavy foundation, it may serve even for heavier traffic. The bitumen used in this treatment penetrates into the wearing out surface of stone particles, thus, coating and binding them together and providing a water proof surface (The Book of Popular Science 1967; Indian Standard Institution 1982). Therefore, it was considered worthwhile to mix the bitumen with magnesium chloride solution in different proportions for achieving similar goals. Investigations were conducted with gauging solution so prepared with a view to finding the effect of the bitumen emulsion on the above noted properties, viz. strength and soundness of magnesia cement products.

\section{Materials}

The following materials were used in this investigation: Magnesia: Commercial grade magnesia used in this study was of Salem (Chennai) origin. It had the following characteristics: (i) bulk density of $0.85 \mathrm{~kg} / \mathrm{l}$, (ii) $95 \%$ passing

\footnotetext{
*Author for correspondence
}

through $75 \mu$ (200 mesh) IS sieve, (iii) minimum $\mathrm{MgO}$ $90 \%$, (iv) $\mathrm{CaO}<1.5 \%$ and (v) loss on ignition at $110^{\circ} \mathrm{C}$ $2.5 \pm 0.5 \%$, dolomite: inert filler (dolomite) with the following characteristics was used: (i) $100 \%$ passing through $150 \mu$ IS sieve, (ii) $50 \%$ retained on $75 \mu$ (200 mesh) IS sieve, (iii) $\mathrm{CaO} 28.7 \%$, (iv) $\mathrm{MgO} 20.8 \%$, (v) insolubles and sesquioxide contents $<1.0 \%$, and (vi) loss on ignition $50 \%$ and magnesium chloride: magnesium chloride $\left(\mathrm{MgCl}_{2} \cdot 6 \mathrm{H}_{2} \mathrm{O}\right)$ used in the study was of ISI grade 3 (IS: 254-1973) with following characteristics: (i) colourless, crystalline, hygroscopic crystals, (ii) highly soluble in water, (iii) magnesium chloride, minimum $\sim 95 \%$ and (iv) magnesium sulphate, and alkali chlorides $(\mathrm{NaCl})$ contents $<4 \%$.

\section{Experimental}

Effect of bitumen emulsion on setting, strength and moisture resistance of oxychloride cement was studied by incorporating it in different amounts in the wet-mix.

\subsection{Setting time test}

Effect of bitumen emulsion on setting characteristics of oxychloride cement was studied by incorporating it in different amounts in trial compositions. Setting periods of the wet-mixes prepared by $1: 2$ dry mixes of diverse compositions separately with the gauging solution were determined adopting the standard procedure (Gupta 1976; Indian Standard Institution 1982). The observed results are summarized in table 1.

\subsection{Weathering test}

Investigations were made by recording variation in weights of the setting time trial blocks (taken from vicat moulds) 
Table 1. Effect of bitumen emulsion on setting characteristics of oxychloride cement.

\begin{tabular}{|c|c|c|c|c|c|c|}
\hline \multirow{2}{*}{$\begin{array}{l}\text { Sl. } \\
\text { no. }\end{array}$} & \multirow[b]{2}{*}{ Observations } & \multicolumn{5}{|c|}{ Composition of dry mix ( $\%$ additive) } \\
\hline & & 0 & 5 & 10 & 15 & 20 \\
\hline & Gauging solution: $22^{\circ} \mathrm{Be}$ & \multicolumn{5}{|c|}{ Temperature: $30^{\circ}$} \\
\hline & Dry-mix composition: $1: 2^{*}$ & \multicolumn{5}{|c|}{ Humidity: Above $75 \%$} \\
\hline 1 & $\begin{array}{l}\text { Volume of gauging } \\
\text { solution }(\mathrm{ml})\end{array}$ & 60 & 58 & 57 & 56 & 56 \\
\hline 2 & Initial setting time (min) & 175 & 180 & 130 & 130 & 140 \\
\hline 3 & Final setting time (min) & 270 & 280 & 290 & 295 & 310 \\
\hline \multirow[t]{3}{*}{4} & Nature of blocks & & & & & \\
\hline & a. Glossiness & Yes & Yes & Yes & Yes & Yes \\
\hline & b. Volume change & Normal & & \multicolumn{2}{|c|}{ slight expansion } & \\
\hline
\end{tabular}

*One part by weight of magnesia and two parts by weight of dolomite

Table 2. Effect of bitumen emulsion on weathering of oxychloride cement.

\begin{tabular}{lllllll}
\hline & & \multicolumn{5}{c}{ Composition of dry mix (\% additive) } \\
\cline { 3 - 7 } $\begin{array}{l}\text { Sl. } \\
\text { no. }\end{array}$ & \multicolumn{1}{c}{ Observations } & 0 & 5 & 10 & 15 & 20 \\
\hline & Gauging solution: $22^{\circ}$ Be & \multicolumn{5}{c}{ Dry mix composition: $1: 2^{*}$} \\
1 & Weight after 24 h (g) & 275 & 278 & 258 & 263 & 265 \\
2 & Weight after 7 days (g) & 270 & 275 & 252 & 295 & 258 \\
3 & Weight after 30 days (g) & 265 & 265 & 242 & 245 & 243 \\
\hline
\end{tabular}

*One part by weight of magnesia and two parts by weight of dolomite

with time 24 h, 7 and 30 days, respectively. Weight of the test blocks may increase or decrease with time due to the different weathering effects promoted by the admixture (Yadav 1989; Gupta et al 1994; Chandrawat and Yadav 2000). The experimental findings are recorded in table 2.

\subsection{Moisture ingress test}

To find out the effect of bitumen emulsion on moisture ingress in oxychloride cement standard setting time blocks were used. These were subjected to moisture treatments (steam test) to estimate their relative moisture sealing efficiencies according to the standard procedure (Yadav 1989; Gupta et al 1990, 1994). The observed results are summarized in table 3 .

\subsection{Compressive strength test}

The way in which incorporation of bitumen emulsion influences compressive strength of the oxychloride cement was studied with the help of standard $50 \mathrm{~cm}^{3}$ cubes prepared from the standard consistency pastes having bitumen emulsion in different amounts. These cubes (moulds) were tested after curing for 30 days as per standard procedures (British Standard 1963; Yadav 1989; Gupta et al 1994). The practical outcomings are shown in table 4 .
Table 3. Effect of bitumen emulsion on moisture ingress (steam test) in the trial blocks.

\begin{tabular}{lcccccc}
\hline \multirow{2}{*}{$\begin{array}{l}\text { S1. } \\
\text { no. }\end{array}$} & Observations & 0 & 5 & 10 & 15 & 20 \\
\cline { 2 - 6 } & Gauging solution: & $22^{\circ}$ Be; & Dry & mix composition: & $1: 2^{*}$ \\
1 & $10 \mathrm{~h}$ & $\mathrm{NE}$ & $\mathrm{NE}$ & $\mathrm{NE}$ & $\mathrm{NE}$ & $\mathrm{NE}$ \\
2 & $15 \mathrm{~h}$ & $\mathrm{NE}$ & $\mathrm{NE}$ & $\mathrm{NE}$ & $\mathrm{NE}$ & $\mathrm{NE}$ \\
3 & $20 \mathrm{~h}$ & $\mathrm{NE}$ & $\mathrm{NE}$ & $\mathrm{NE}$ & $\mathrm{NE}$ & $\mathrm{NE}$ \\
4 & $25 \mathrm{~h}$ & $\mathrm{NE}$ & $\mathrm{NE}$ & $\mathrm{NE}$ & $\mathrm{NE}$ & $\mathrm{NE}$ \\
5 & $30 \mathrm{~h}$ & $\mathrm{C}$ & $\mathrm{NE}$ & $\mathrm{NE}$ & $\mathrm{NE}$ & $\mathrm{NE}$ \\
6 & $35 \mathrm{~h}$ & - & $\mathrm{C}$ & $\mathrm{C}$ & $\mathrm{C}$ & $\mathrm{C}$ \\
\hline
\end{tabular}

* One part by weight of magnesia and two parts by weight of dolomite (NE: no effect; C, cracked)

\subsection{Soundness test}

This test was carried out with the Le-chateliers test apparatus, which consists of small split cylinder forming a mould and two glass plates to cover each side of the cylinder. Two parallel indicating arms with pointed ends are attached on either side. The wet-mix, which is to be tested for the soundness of the product, is placed into the mould resting on a glass plate and then covered with another glass plate. The wet-mix is then allowed to set for one week, then difference $(x)$ between pointed ends of the indicating arms is measured. Now the mould is immersed 
in water at $27-32^{\circ} \mathrm{C}$ for $48 \mathrm{~h}$. Again, the distance $(x)$ between pointed ends of the indicating arms is measured. Then the mould is immersed in a beaker of boiling water for $1 \mathrm{~h}$, cooled and again the distance $(y)$ measured. The difference $(y-x)$ measures the soundness or expansion of the product. The value of $(y-x)$ should not be more than $5 \mathrm{~mm}$ for a good product (Gupta 1976; Yadav 1989; Chandrawat et al 1994). The results of the investigation are summarized in table 5 .

\section{Discussion}

Table 1 reveals the effects of bitumen emulsion on setting characteristics of oxychloride cement. The volume of gauging solution decreases constantly with its increasing proportion. This may be due to the correspondingly decreasing proportion of magnesium chloride (gauging solution) or increasing proportion of water in the gauging solution. Under such a situation less and less amount of gauging solution is required to maintain the same consistency. Initial setting time remains almost unaffected when bitumen emulsion is admixed in small proportions (up to $5 \%$ ). Futher increase in its relative amount is witnessed by sudden fall of initial setting periods to almost a constant value within the experimental limits. This may be attri- buted to opposing effects of decreasing relative amounts of magnesium chloride or increasing proportions of water (both factors decrease initial setting time) and increasing proportion of bitumen (which increases initial as well as final setting). Cross effect of these parameters is to retard formation of strength giving composition (magnesia cement). Accordingly, a constant increase in final setting periods is expected. Low heat evolved due to slowed down setting and increasing chances of remaining unused magnesia in the matrix contribute to glossiness of the surface and slight expansion of the blocks.

Table 2 shows the effect of weathering on the admixture. It is found that the weight of the blocks decreases regularly with passage of time, $24 \mathrm{~h}, 7$ and 30 days. This happens due to a slowed down setting and tendency of bitumen to retain moisture. As such a lot of moisture still remains in the blocks even after the setting is completed and moisture evaporates only slowly. Hence, almost uniform loss in weights with time is expected (table 2). Petroleum products are known hydrophobic compounds. They resist moisture ingress. Accordingly, it is noted that incorporation of bitumen emulsion in magnesia cement improves its water tightness to a great extent (table 3). This phenomenon checks weathering effects to some extent. Hence, it is noted that in small proportions bitumen emulsion contributes to compressive strength (table 4).

Table 4. Effect of bitumen emulsion on compressive strength of oxychloride cement.

\begin{tabular}{|c|c|c|c|c|c|c|}
\hline \multirow{3}{*}{$\begin{array}{l}1 \\
2\end{array}$} & \multirow{2}{*}{$\begin{array}{l}\text { Gauging solution: } 24^{\circ} \mathrm{Be} \\
\% \text { Additive (bitumen emulsion) }\end{array}$} & \multicolumn{5}{|c|}{ Dry mix composition: $1: 2 *$} \\
\hline & & 0 & 5 & 10 & 15 & 20 \\
\hline & Compressive strength $\left(\mathrm{kg} / \mathrm{cm}^{2}\right)$ & 480 & 660 & 580 & 492 & 310 \\
\hline
\end{tabular}

*One part by weight of magnesia and two parts by weight of dolomite

Table 5. Effect of bitumen emulsion on soundness of oxychloride cement (Le-Chatelier's test).

\begin{tabular}{|c|c|c|c|c|c|c|c|c|}
\hline \multirow{2}{*}{$\begin{array}{l}\text { Sl. } \\
\text { no. }\end{array}$} & \multirow[b]{2}{*}{ Observations } & \multicolumn{7}{|c|}{ Additive (\%) } \\
\hline & & 0 & 5 & 10 & 15 & 20 & & \\
\hline & Gauging solution: $24^{\circ} \mathrm{Be}$ & \multicolumn{7}{|c|}{ Dry mix composition: $1: 2^{*}$} \\
\hline 1 & Weight of cement composition (g) & & & & & & & \\
\hline & (i) Magnesia & 13 & $13 \cdot 0$ & $13 \cdot 0$ & $13 \cdot 0$ & $13 \cdot 0$ & & \\
\hline & (ii) Dolomite & 26 & $24 \cdot 7$ & $23 \cdot 4$ & $22 \cdot 1$ & $20 \cdot 8$ & & \\
\hline & (iii) Additive & Nil & $1 \cdot 3$ & $2 \cdot 6$ & $3 \cdot 9$ & $5 \cdot 2$ & & \\
\hline 2 & Use of $\mathrm{MgCl}_{2}$ solution (ml) & & $11 \cdot 5$ & $10 \cdot 0$ & $10 \cdot 0$ & $10 \cdot 0$ & $10 \cdot 0$ & \\
\hline 3 & $\begin{array}{l}\text { Distance between two pointers before } \\
\text { starting }(\mathrm{cm})\end{array}$ & & $1 \cdot 8$ & $2 \cdot 3$ & $3 \cdot 2$ & $1 \cdot 3$ & $1 \cdot 5$ & \\
\hline 4 & $\begin{array}{l}\text { Distance between two pointers } \\
\text { after } 7 \text { days }(\mathrm{cm})\end{array}$ & & & $2 \cdot 0$ & $2 \cdot 4$ & $3 \cdot 1$ & $1 \cdot 2$ & $1 \cdot 4$ \\
\hline 5 & Time in water at $27^{\circ}$ to $32^{\circ} \mathrm{C}(\mathrm{h})$ & & $48 \cdot 0$ & $48 \cdot 0$ & $48 \cdot 0$ & $48 \cdot 0$ & $48 \cdot 0$ & \\
\hline 6 & $\begin{array}{l}\text { Distance between two pointers } \\
\text { before boiling }(\mathrm{cm})\end{array}$ & & & $2 \cdot 2$ & $2 \cdot 4$ & $3 \cdot 1$ & $1 \cdot 2$ & $1 \cdot 5$ \\
\hline 7 & $\begin{array}{l}\text { Distance between two pointers } \\
\text { after boiling }(\mathrm{cm})\end{array}$ & & & $2 \cdot 3$ & $2 \cdot 5$ & $3 \cdot 2$ & $1 \cdot 3$ & $1 \cdot 6$ \\
\hline 8 & Expansion of cement $(\mathrm{cm})$ & & $0 \cdot 1$ & $0 \cdot 1$ & $0 \cdot 1$ & $0 \cdot 1$ & $0 \cdot 1$ & \\
\hline
\end{tabular}

*One part by weight of magnesia and two parts by weight of dolomite 
However, subsequent additions are witnessed by a constant fall in strengths of the trial blocks. This owes to correspondingly decreasing proportions of magnesium chloride in dry-mixes and less chances for the formation of strength giving compositions (oxychloride cement).

The aforesaid findings are further supported by the investigation pertaining to the effects of bitumen emulsion on soundness of oxychloride cement (table 5). When used in excess, slight expansion in the bulk volume of trial blocks is expected on account of the increasing chances of remaining unused magnesia in the matrix. This unused magnesia hydrates expansively and forms magnesium hydroxide.

\section{Conclusions}

(I) In small proportions bitumen emulsion improves strength and soundness of the products.

(II) However, in excess (beyond 10\%) its incorporation is harmful.

\section{References}

Beaudin J J and Ramachandra V S 1975 Chem. Concer. Res. 5 617

Beaudin J J, Ramachandra V S and Feldmand R F 1977 Am. Ceram. Soc. Bull. 424
British Standard 1963 Specification of materials for magnesium oxychloride flooring, BS: 776

Chandrawat M P S and Yadav R N 2000 Bull. Mater. Sci. 2369

Chandrawat M P S, Yadav R N and Mathur Ritu 1994 Res. \& Ind. 3918

Gupta B L 1976 Concrete technology (New Delhi: Standard Publisher) p. 18

Gupta Y K, Chandrawat M P S and Yadav R N 1990 Res. \& Ind. 35191

Gupta Y K, Chandrawat M P S and Yadav R N 1994 Proc. NASI A64 200

Indian Standard Institution 1982 Method of test for materials for use in the preparation of magnesium oxychloride flooring composition, IS: 10132

Indian Standard Institution 1982 Specification for materials for use in the preparation of magnesium oxychloride flooring composition, IS: 657

Mathur Renu 1986 Effect of temperature on calcination of magnesite properties of oxychloride cement, Ph.D. Thesis, University of Rajasthan, Jaipur

Matkovic B, Po Pvic S, Rogic V and Zunic T 1977 J. Am. Ceram. Soc. 60504

Sorel S T 1867 Comp. Rend. 65102

The Book of Popular Science 1967 Grolier Incorporated, New York, USA 3297

Ved E I, Zharov F F, Ragacheva I N and Bacharov V R 1976 Chem. Abstr. 85824

Yadav R N 1989 Effect of some additives on setting, strength and moisture resistance of oxychloride cement, Ph.D. Thesis, University of Rajasthan, Jaipur 